\title{
Correction to: Influence of Exogenous Silicon Addition on Aluminium Tolerance in Rice Seedlings
}

\section{Vijay Pratap Singh ${ }^{1} \cdot$ Durgesh Kumar Tripathi ${ }^{2} \cdot$ Dharmendra Kumar $^{2} \cdot$ Devendra Kumar Chauhan $^{2}$}

Published online: 15 May 2020

(C) Springer Science+Business Media, LLC, part of Springer Nature 2020

Correction to: Biological Trace Element Research. https://doi.org/10.1007/s12011-011-9118-6

The original version of this article unfortunately contained a mistake. The updated version of Fig. 7 is presented here.

The online version of the original article can be found at https://doi.org/ 10.1007/s12011-011-9118-6

\footnotetext{
Devendra Kumar Chauhan dkchauhanau@yahoo.com

Vijay Pratap Singh

vijaypratap.au@gmail.com

Durgesh Kumar Tripathi dktripathiau@gmail.com

1 Ranjan Plant Physiology and Biochemistry Laboratory, Department of Botany, University of Allahabad, Allahabad 211002, India

2 Palaeobotany and Morphology Laboratory, Department of Botany, University of Allahabad, Allahabad 211002, India
} 

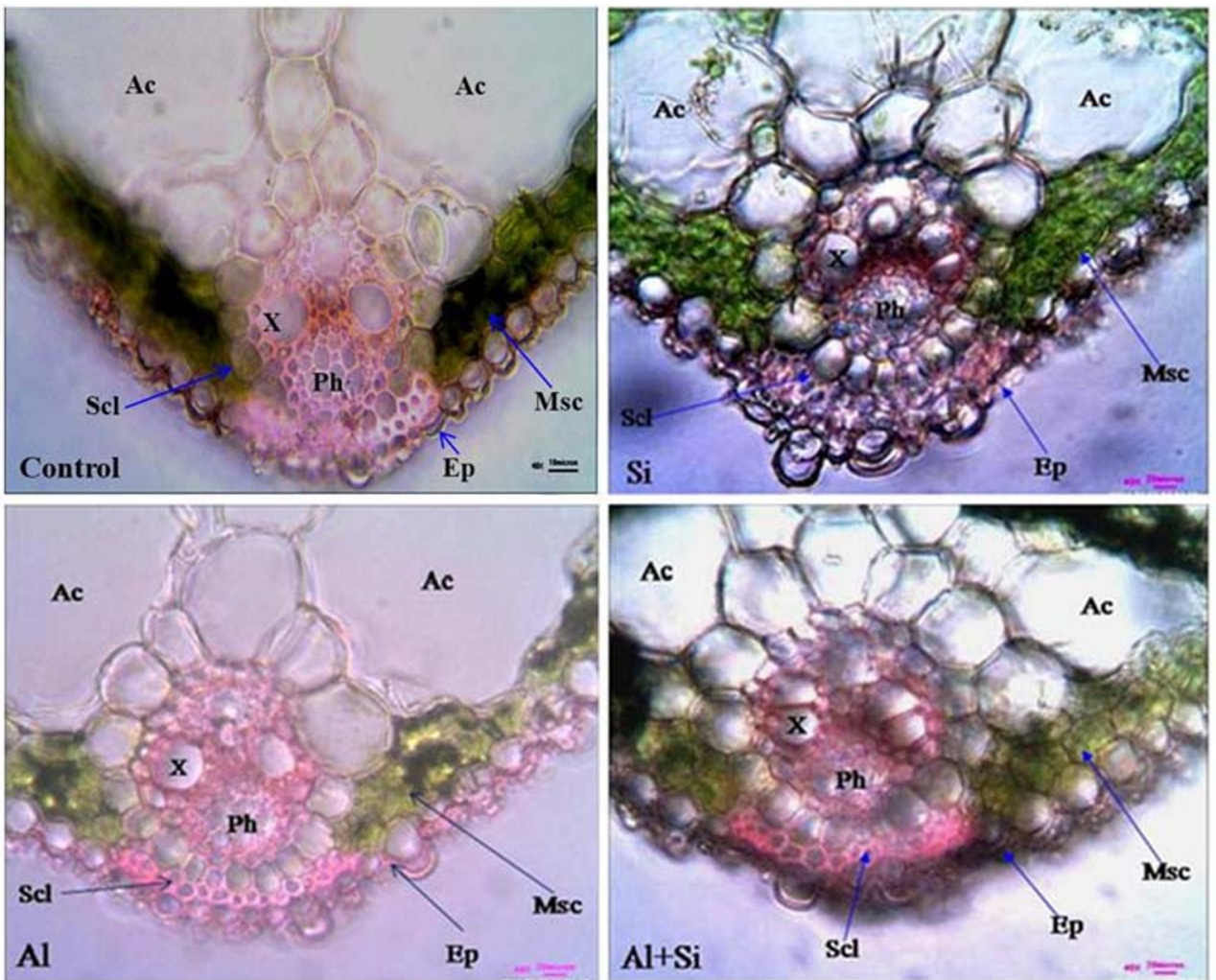

Publisher's Note Springer Nature remains neutral with regard to jurisdictional claims in published maps and institutional affiliations. 